\title{
O SONHO DE DESCARTES E O DESPERTAR DE KANT
}

\author{
[DESCARTES'S DREAM AND KANT'S AWAKING UP]
}

José Antônio Zago *

RESUMO: A partir de dados do terceiro sonho de Descartes escrito num caderno de notas (Olympica) e do entendimento do despertar do sono dogmático de Kant conforme aponta nos Prolegômenos a qualquer metafísica futura, o autor faz conjecturas sobre os dois filósofos num campo não interferente de reflexão.

Palavras-ChaVe: Descartes; conjecturas; epistemologia
ABSTRACT: From Descartes information of the third dream written in a notebook (Olympica) and of understanding dogmatic sleep awakening Kant as points in the Prolegomena to any future metaphysics, the author makes conjectures about the two philosophers in a non-interfering field reflection.

Kant; KeYwords: Descartes; Kant; Conjecture; Epistemology

\section{INTRODUÇÃO}

R ené Descartes nasceu em 1596 em La Haye, França e faleceu em REstocolmo, Suécia, em 1650. Foi educado no aristotelismo tradicional no colégio jesuíta La Fleche. Serviu como soldado na Holanda e deixou o exército em 1621 para se dedicar à ciência e à filosofia. De 10 para 11 de novembro de 1619 , quando se encontrava em Ulm, Alemanha, fechou-se num quarto e teve três sonhos, acreditando ser uma revelação divina sobre o trabalho filosófico a que se dedicaria. Mudou-se para a França, mas em 1629 voltou par a Holanda.

Em 1637 publicou Discurso do método, cuja segunda parte reporta sua estada na Alemanha em 1619 e a possibilidade da construção do edifício de uma ciência admirável. Em 1639 iniciou as Meditações, considerada sua obra mais importante. Sua intenção era escrever para o público leigo, por isso escrevia em francês e não em latim como era o costume entre os estudiosos da época. Em 1648 aceitou convite da Rainha Cristina da Suécia para ser seu preceptor (PADOVANI; CASTAGNOLA, 1974; RAEPER; SMITH, 2001).

Immanuel Kant nasceu em 22 de abril de 1724 e faleceu em 12 de fevereiro de 1804 em Königsberg na antiga Prússia, atual Kaliningrado, Rússia. Estudou no colégio Fredericianum e filosofia na Universidade de Königsberg onde se tornou catedrático de matemática e lógica. Diferentemente de Descartes, Kant nunca saiu de sua cidade natal.

* Psicólogo e Mestre em Filosofia da Educação (Universidade Metodista de Piracicaba). Licenciado em Filosofia (Centro Universitário Claretiano). Professor de Psicologia e Filosofia do Centro de Estudos Superiores de Campinas, lecionando no Instituto de Ensino Superior de Itapira(IESI).m@ilto: joseantoniozago@hotmail.com 
Sua obra considerada a mais importante, Crítica da razão pura, publicada em 1781, levou cerca de dez anos para ser escrita. Dentre vários textos de Kant destacamos: Crítica da razão prática (1788) e Crítica do juízo (1790).

Em Prolegômenos a qualquer metafisica futura que possa apresentar-se como ciência Kant afirmou que até ler David Hume era igual a qualquer pensador metafísico, já que para Hume as relações de causa e efeito não podem ser demonstradas racionalmente, pois são hábitos. Ao ler Hume, Kant disse que foi desperto do sono dogmático ao descobrir "[...] que o conceito de conexão de causa e efeito está longe de ser o único pelo qual o entendimento pensa as conexões entre as coisas, e, mais ainda, descobri que a metafísica consiste inteiramente nesses conceitos." (KANT, 2014, p. 28). A curiosidade filosófica entre os termos sonhar/despertar despertou o objetivo de apreciar o estado da construção do conhecimento proposta por Descartes e Kant, já que tanto os sonhos de um quanto o despertar do outro são nesse rumo. Que poderia ser conjecturado disso?

\section{O SONHO DE DESCARTES}

Segundo Buff (2001) Descartes escreveu seus sonhos num caderno de pergaminho, onde constava outras anotações, sob o nome de Olympica. Embora inventariado, o caderno, com notas sem sequência ou notas descontínuas, foi perdido, mas seu biógrafo e amigo padre Adrien Baillet teve às mãos esses escritos e relata então os sonhos e a interpretação do próprio Descartes. Leibniz foi outro que leu os escritos e copiou partes dele.

A data das Olympica está escrita nas primeiras linhas: "X Novembris 1619, cum plenus forem Enthousiasmo \& mirabilis fcientiae fundamenta reperirem \& c.". Ainda, outra data consta também, contudo na margem do texto "XI Novembris 1620" escrita com tinta mais recente. Uma das hipóteses é que a data após quase no mesmo dia a um ano dos sonhos era significativa porque Descartes havia feito uma de suas descobertas. Por essa feliz coincidência registrou no caderno, que também era uma espécie de diário: "X Novembris 1619, cum plenus forem Enthousiasmo \& mirabilis fcientiae fundamenta reperirem - XI Novembris 1620, coepi intelligere fundamentum Inventi mirabilis". Tanto Baillet quanto outros autores sustentam que a data 10 de novembro de 1619 como a data em que os sonhos ocorreram (BUFF, 2001, p. 50).

Descartes registrou no caderno, em 10 de novembro de 1619, que se deitou entusiasmado e com o pensamento todo ocupado "por haver achado naquele dia os fundamentos de uma ciência admirável, teve três sonhos consecutivos numa só noite, que imaginou terem vindo do alto." (BUFF, 2001, p. 210).

O estudo de Buff (2001) apresenta várias nuances dos sonhos, além da própria interpretação de Descartes, e de outros como Freud e Jean-Luc Marion, bem como uma elaboração de um paralelo entre a interpretação cartesiana e a bergsoniana discutida no texto:

O objetivo da primeira (cartesiana) é, portanto, a busca da relação entre os sonhos e pensamentos de Descartes, o caráter filosófico dos sonhos e sua integração no corpus filosófico, ao passo que na segunda (bergsoniana) é a relação entre os sonhos e a vida de Descartes sob a ótica da análise dos instantes no tempo. O valor dos sonhos é dado a posteriori, pela autointerpretação, segundo o primeiro enfoque, mas no segundo tem o seu valor a priori (BUFF, 2001, p.182)

Freud (1973) também examinou os sonhos de Descartes, a pedido de Maxime Leroy para seu livro Descartes, le Philosophie au Masque, publicado em Paris em 
1929, não encontrando significados profundos (no sentido de inconsciente) nos sonhos, mas entendeu-os como "sonhos do alto" ou próximos da consciência; ideações que também poderiam ser criadas facilmente no estado de vigília, semelhantes, por exemplo, a poesia. Freud manifestou que os sonhos pudessem representar em parte um conflito interior. Valorizou a própria interpretação de Descartes, já que nesse tipo de sonho deve-se compreender o sonhador. Além disso, apontou a dificuldade de uma interpretação psicanalítica de fato ao referir-se a um personagem histórico.

Neste estudo atentamos na interpretação do próprio Descartes, portanto, $a$ posteriori, e apenas no terceiro sonho, já que ele possibilita a integração de seu significado na obra filosófica de Descartes, ou seja, como o princípio motivador da obra, talvez até com um sentido místico que o próprio Descartes atribuiu. Descartes havia interpretado os dois sonhos anteriores como avisos ameaçadores quanto à sua vida passada por não ter sido inocente perante Deus, mas que o terceiro sonho era muito doce e agradável e abria o futuro. Passado o pavor do segundo sonho, Descartes readormeceu calmo e teve o terceiro sonho, conforme escrito no Apêndice Olympica (apud BUFF, 2001, p. 209-216):

[...] achou um livro sobre a mesa, sem saber quem o tinha colocado ali. Ele o abriu, e vendo que era um Dicionário, se alegrou muito na esperança que ele lhe poderia ser muito útil. No mesmo instante, encontrou outro livro sob sua mão, que também não lhe era desconhecido, não sabendo de onde lhe havia aparecido. Pensou ser uma antologia de poesias de diferentes autores, intitulada Corpus poetarum [na margem: dividido em 5 livros, impresso em Lyon e Genebra]. Ele teve a curiosidade de nele querer ler alguma coisa, e na abertura do livro ele se deteve sobre o verso Quod vitae sectabor iter? etc. No mesmo momento, percebeu um homem que ele não conhecia, mas que lhe apresentou uma peça de versos começando por Est et Non, e que a ele exaltava como uma peça excelente. O senhor Descartes lhe diz que sabia o que era e que esta peça estava entre os "Idílios" de Ausônio que se encontrava na grande Antologia de Poetas que estava sobre a mesa. Ele mesmo quis mostra-la a este homem, e se pôs a folhear o livro do qual ele se gabava de conhecer perfeitamente a ordem e a economia. Enquanto procurava o lugar, o homem perguntou-lhe onde ele havia pego o livro e o senhor Descartes respondeu-lhe que não podia lhe dizer como o obteve, mas que um momento antes manuseou ainda um outro que tinha acabado de desaparecer, sem saber quem o havia levado, nem quem o havia pego novamente. Ele não tinha acabado de dizer quando viu novamente aparecer o livro na outra ponta da mesa. Mas ele observou que este Dicionário não estava mais completo como tinha visto na primeira vez. Entretanto, se deparou com as poesias de Ausônio na Antologia dos Poetas que ele folheava, e não conseguindo achar a peça que se principia por Est et Non, ele diz a esse homem que ele conhecia uma do mesmo poeta ainda mais bela que esta e que ela começava por Quod vitae sectabor iter?. A pessoa pediu para lhe mostrar e o senhor Descartes se considerou obrigado a procura-la, quando ele encontrou diversos retratinhos gravados em talha-doce, o que lhe fez dizer que esse livro era bem bonito, mas não era da mesma impressão que aquele outro que ele conhecia. Estava nesse ponto, quando os livros e o homem sumiram e se apagaram da sua imaginação, sem contudo acordá-lo. O que há de singular para notar, é que, duvidando se o que ele acabara de ver era sonho ou visão, não somente decidiu dormindo que era um sonho, mas ainda ele o interpretou antes que o sono o deixasse. Julgou que o Dicionário não queria dizer outra coisa do que todas as ciências reunidas num todo, e que a Antologia de Poesias intitulada Corpus poetarum mostrava, em particular e de maneira mais distinta, a filosofia e a sabedoria reunidas. Pois ele não acreditava que nós nos admiremos tanto de ver que os poetas, mesmo os que nada mais fazem do que bobagens, fossem cheios de sentenças mais graves, mais sensatas, e melhor 
expressas do que aquelas que se encontram os escritos dos filósofos. Ele atribuía esta maravilha à divindade de Entusiasmo e à força da Imaginação que faz surgir as sementes da sabedoria (que se encontram no espírito de todos os homens como as fagulhas de fogo nas pedras) com muito mais facilidade, e muito mais brilhantismo mesmo, do que pode fazer a Razão nos filósofos. O senhor Descartes, continuando a interpretar seu sonho durante o sono, entendia que a peça de versos sobre a incerteza do gênero de vida que devemos escolher, e que começa por Quod vitae sectabor iter, marcava o bom conselho duma pessoa sábia, ou mesmo a Teologia Moral.

Então, duvidando se sonhava ou meditava, ele despertou sem emoção e continuou, de olhos abertos, a interpretação de seu sonho sobre a mesma ideia. Quanto aos poetas reunidos na ontologia ele entendia a Revelação e o Entusiasmo, pelos quais ele não perdia a esperança de ser favorecido. Quanto à peça de versos Est et Non, que é o Sim e o Não de Pitágoras [à margem nai kai ou], ele compreendia a Verdade e a Falsidade nos conhecimentos humanos e as ciências profanas. Vendo que a aplicação de todas estas coisas se resolviam tão bem conforme a sua vontade, ele foi suficientemente ousado para se persuadir que era o Espírito da Verdade que quis lhe abrir os tesouros de todas as ciências por meio deste sonho. E como só lhe faltava explicar os pequenos retratos gravados em talha-doce e que ele havia encontrado no segundo livro, não procurou mais explicações, depois da visita que um pintor italiano lhe fez no dia seguinte (apud BUFF, 2001, p. 212-213)

Buff (2001, p. 17-19) assinala que o episódio onírico provocou em Descartes meditações e reflexões importantes para a sua vida como um chamado vocacional para a filosofia. Esse dia e essa noite de 10 de novembro de 1619, a autora argumenta também como que uma síntese do diurno pela descoberta dos fundamentos de uma ciência admirável (mirabilis scientiae fundamenta) com o noturno pelo conteúdo dos sonhos: síntese de "[...] dia e noite, racionalidade e irracionalidade, passividade e liberdade, luz e sombra, sentido e não sentido, espírito e corpo."

Ora, o que se vê nessa síntese são duplas contrárias e que de certa maneira se complementam. Dito de outro modo, dualismos como espírito e corpo ou alma e corpo a base das ideias cartesianas: substância extensa e substância pensante.

\section{DESCARTES E O RACIONALISMO}

O método cartesiano, analítico, gradual, com início na intuição e de cadeias de razões, isto é, dedutivo (evidência, análise, síntese e enumeração) parte da dúvida hiperbólica e do fundamento do cogito como fonte do conhecimento, já que os sentidos, e tudo o mais, poderiam ser fontes de erros ou enganos. Para Descartes, Deus é a substância infinita, fundamentando toda a sua filosofia na separação mente/corpo (dualismo): substância pensante e substância extensa. Pretendeu construir um conhecimento universal e seguro, com base na matemática.

Meditações é o trabalho no qual Descartes tenta demonstrar a existência de Deus e a distinção entre alma e corpo do homem.

Na Segunda Meditação, composta de 18 parágrafos, Descartes trata da Natureza do Espírito Humano e de como é mais fácil conhecer o espírito que o corpo.

Descartes considera, incialmente, que se ele encontrar algo certo ou indubitável, ou seja, o fundamento ou a substância, será semelhante a proposta de Arquimedes que se lhe dessem um ponto fixo poderia mover o mundo.

Descartes parte da dúvida ou em duvidar de tudo para alcançar uma certeza. 
Duvida dos sentidos, já que eles podem ser fontes de engano; duvida da realidade exterior, o sonho da realidade, duvida do próprio corpo, do vento, do fogo, nem de nenhuma coisa imaginada, de um Gênio Maligno, embora a imaginação faça parte do pensamento. Para Descartes o pensamento é distinto dos corpos e de tudo que é material e distinto também de faculdades não necessariamente intelectuais, como é o caso do imaginar. Tudo para Descartes são fícções do espírito. Trata-se de dúvida hiperbólica, de um caminho para alcançar a certeza, conforme aponta no Discurso do Método (DESCARTES, 1973a, p. 54).

A certeza a qual chega Descartes é despida de tudo conforme mencionado no parágrafo precedente, e é a primeira verdade: “(...) eu sou, eu existo, é necessariamente verdadeira todas as vezes que enuncio ou que concebo em meu espírito." (DESCARTES, 1973b, p. 100). Assim, a partir dessa primeira verdade ou certeza, Descartes refere que o homem é uma coisa pensante, ou seja, um espírito, alma, intelecto ou razão. Uma coisa pensante, portanto puro pensamento exclusivo do corpo, alcançando aí a segunda certeza. Contudo, somente na Sexta Meditação é que Descartes fará a distinção entre alma e corpo (DESCARTES, 1973b, Nota 37, p. 103).

Ao levantar a questão "O que sou eu, portanto ou que é uma coisa que pensa", Descartes apresenta as funções do espírito: "É uma coisa (a substância espírito) que duvida, que compreende, que afirma, que nega, que quer, que não quer, que também imagina, e que sente" (p. 103). Faz-se necessário apontar o conteúdo da Nota 38 (DESCARTES, 1973b, p. 103) que os modos imaginar, sentir e querer, apesar de não pertencerem "à minha natureza que é puro pensamento exclusivo de todo elemento corporal", ou seja, à essência da coisa pensante, por beneficiarem da certeza do cogito não podem ser postos em dúvida. Por assim dizer, esses modos são reintegrados à coisa pensante.

Assim, Descartes faz uma divisão da coisa que pensa e a da coisa extensa (coisa extensa, corpo, mundo). Discute que erroneamente acreditamos que as coisas extensas são mais fáceis de conhecer. Para discordar disso, Descartes apresenta o exemplo do pedaço de cera que ao ser aproximado do fogo perde suas características conhecidas pelos sentidos. As características observáveis da cera mudam, mas permanece algo, ou seja, o entendimento pela razão do objeto, que subjaz às mudanças de propriedades dos objetos. Neste exemplo Descartes mostra que a coisa pensante, o espírito, permanece enquanto substância independente das mudanças das propriedades do objeto:

[...] só concebemos os corpos pela faculdade de entender em nós existentes e não pela imaginação nem pelos sentidos, e que não os conhecemos pelo fato de os ver ou de tocá-los, mas somente por os conceber pelo pensamento, reconheço com evidência que nada há que me seja mais fácil de conhecer do que meu espírito. (DESCARTES, 1973b, p. 106).

Para Descartes, enfim, o conhecimento somente pode ser pelo entendimento ou pela razão e, assim, chega à terceira certeza ou verdade que nada está mais próximo da mente do que ela própria.

\section{O DESPERTAR do SONO DOGMÁtico DE KANT}

Na Crítica da Razão Pura Kant (1999, p. 54) parte da afirmação que "Somos possuidores de certos conhecimentos a priori e mesmo o entendimento comum jamais está desprovido dele", justificando que se um juízo é argumentado com rigorosa universalidade, vale como conhecimento sintético a priori porque nessas condições não é derivado da experiência, pois esta nunca dá universalidade verdadeira aos seus juízos. 
Demonstra que as proposições matemáticas é um exemplo das ciências de que toda mudança tem uma causa. É nesse sentido que discorda da frequente associação de David Hume (1711-1776) do que acontece como resultado de que antecede, que são hábitos e não fruto da razão.

Aponta que Hume levantou a questão sobre a metafísica atentando-se somente na proposição sintética da conexão causa e efeito, sublinhando, porque segundo Kant, Hume não percebeu a questão da universalidade, cujas conclusões implicou na destruição da filosofia pura, o que derivaria de seus argumentos que não poderia haver também uma matemática pura. Assim, a posição cética de Hume ou o problema de Hume, de que um único conceito da metafísica, a conexão de causa e efeito, é impossível ser pensada pela razão a priori, mas apenas justificada pelo hábito, e essa argumentação mostrou-se a princípio irrefutável, tornou-se um dogma já que o ceticismo de Hume imobilizou as pretensões de um conhecimento puro apenas pela razão.

Esse dogma é quem fez adormecer a crítica, sendo aceito na história das ideias sem maiores questionamentos. Entretanto, é com Kant que a crítica é retomada e esse retomar da crítica é o despertar do sono dogmático, como revelou Kant: Admito sem hesitar: a recordação de David Hume foi extamente aquilo que, há muitos anos, primeiro interrompeu meu sono dogmático e deu uma direção completamente diversa às minhas investigações no campo da filosofia especulativa (KANT, 2014 p. 28).

Esse despertar do sono dogmático foi o motivo para Kant escrever a Crítica da razão pura. Trata-se de uma teoria do conhecimento onde Kant argumenta que tanto a razão quanto os sentidos, ou tanto a razão pura quanto a experiência são importantes para o conhecimento:

Mas embora todo o nosso conhecimento comece com a experiência, nem por isso todo ele se origina $d a$ experiência. Pois poderia bem acontecer que mesmo o nosso conhecimento de experiência seja um composto daquilo que recebemos por impressões e daquilo que a nossa própria faculdade de conhecimento (apenas provocada por impressões sensíveis) fornece de si mesma, cujo alimento não distinguimos daquela matéria-prima antes que um longo exercício nos tenha tornado atento a ele e nos tenha tornado aptos à sua abstração (KANT, 1999, p. 53).

Kant deixa evidente que o conhecimento começa com a experiência, mas nem todo tem sua origem aí. Ou seja, a razão pura também pode ser origem de conhecimento. São esses trilhos teóricos que Kant percorreu para desenvolver a Crítica da razão pura e concomitante a questionar Hume:

Na solução do problema precedente (o problema de Hume) está ao mesmo tempo incluída a possibilidade de o uso puro da razão fundar e levar a cabo todas as ciências que contêm um conhecimento teórico a priori de objetos, isto é, responder às perguntas:

Como é possível a matemática pura?

Como é possível a ciência pura da natureza? (KANT, 1999, p. 63).

\section{KANT E O EMPIRISMO MODIFICADO}

Descartes inaugurou o racionalismo moderno ao demonstrar que podemos explicar a natureza e o mundo apenas com a razão. Essa explicação clara da natureza, 
que parte da dúvida para analiticamente chegar à certeza, demonstra que os sentidos podem nos conduzir a erros e enganos. No exemplo do pedaço de cera fica demonstrado por Descartes que eu penso perceber o pedaço de cera, isto é, o pensamento ou a razão é indispensável ao conhecimento da coisa ou da matéria extensa. $\mathrm{O}$ pensamento como fundamento ou substância, bem como suas funções, muito bem esclarecido pelo exemplo do pedaço de cera; e da cadeia de razões que começa pela primeira verdade: eu penso, eu existo, deduzindo as duas verdades seguintes: sou uma coisa pensante, puro pensamento exclusivo do corpo e as coisas da mente ou do espírito são mais fáceis de conhecer porque nada está mais próximo do espírito que ele próprio (DESCARTES, 1973b). Portanto para o racionalismo o conhecimento somente é possível pela razão.

Entretanto, para o empirismo o conhecimento somente pode ser pela observação e pela experiência. $\mathrm{O}$ empirismo começa a ganhar contornos mais precisos com Francis Bacon (1561-1626) e aprimora-se com John Locke (1632-1704) e Hume.

Kant viveu num clima tenso no que se refere à origem do conhecimento, tentando superar o impasse, já que na época tanto racionalistas como Descartes, Baruch Spinoza (1632-1677), Gottfried Wilhelm Leibnitz (1646-1716) e Christian Wolf (16791754) quanto empiristas como Locke e Hume reivindicavam essa exclusividade. Kant postulou que todo conhecimento está relacionado com a experiência, contudo, nem tudo que conhecemos pode ser atribuído a essa origem já que existe conhecimento não ligado com aquilo que experimentamos (ZAGO, 2014).

Popper apresenta de forma cristalina a proposta kantiana de unificação sobre a origem do conhecimento e suas limitações pela razão pura:

A síntese de Kant era uma forma modificada de empirismo. O seu principal objetivo consistia em refutar o racionalismo puro. Na sua "Kritik der reinen Vernunft" (Crítica da Razão Pura) afirmava que o âmbito do nosso conhecimento se restringia ao domínio da experiência possível e que o pensamento especulativo - uma construção de um sistema metafísico pela razão pura - não se podia justificar para além deste domínio. [...] Numa parte de sua Crítica, que ele intitula "Dialética Transcendental" demonstra o seguinte: quando tentamos construir um sistema teórico a partir da razão pura - exemplificando - quando tentamos argumentar que o mundo em que vivemos é infinito, (uma noção que evidentemente ultrapassa os limites da experiência possível) então podemos fazêlo; porém, asseveraremos, também, para consternação nossa, que, com a ajuda de argumentos análogos podemos sempre provar exatamente o contrário. Em outras palavras: quando consideramos uma tese metafísica deste gênero, podemos sempre construir e defender uma antítese correta; e para cada argumento a favor da tese podemos, sem dificuldade, construir um argumento contrário a favor da antítese. E ambos os argumentos serão da mesma intensidade e terão o mesmo poder de convicção. Deste modo, assim diz Kant, a razão vê-se obrigada a contradizer-se a si própria sempre que é usada para além da experiência possível (POPPER, 1981, p. 38 e 40)

Assim, a principal tese de Kant é que a mente não é à semelhança de uma cera na qual as sensações escrevem a bel prazer; mas "um órgão que transforma a caótica multiplicidade da experiência na unidade ordenada do pensamento". (DURANT, 1966, p. 257). E nisso consiste o que ele denominou sua proposta sobre o conhecimento de revolução copernicana:

Se a intuição tivesse que se regular pela natureza dos objetos, não vejo como se poderia saber algo a priori a respeito da última; se porém o objeto (Gegenstand) (como objeto (objekt) dos sentidos) se regula pela natureza de nossa faculdade de intuição, posso então representar-me muito bem essa possibilidade (KANT, 1999, 
p. 39).

Se Copérnico demonstrou que o centro do mundo era o sol, Kant, analogamente demonstrou que no processo do conhecimento o sujeito do conhecimento pode conhecer o mundo da forma que a razão ou o pensamento o entende. Com Kant a origem do conhecimento é deslocada do objeto para o sujeito, não o sujeito cartesiano, mas um sujeito transcendental.

\section{SONHO E DESPERTAR: CONJECTURAS}

O método de Descartes rompeu com o aristotelismo, anunciando a filosofia moderna e evidenciando que o conhecimento somente era possível pela razão, a qual contém ideias inatas, separando o sujeito do objeto do conhecimento.

Entretanto, o conhecimento pode ser tanto pela razão quanto pela experiência, conforme Kant (1999) debateu em sua principal obra. Acrescenta-se que Descartes evidentemente não conheceu o que Kant escreveu, mas Kant possivelmente pôde ler toda a obra de Descartes e o considerar como representante do "idealismo cético" (KANT, 2014, p. 163). Kant (1999, p. 61), ainda, pôde conhecer a obra de Isaac Newton (1643-1727) sobre a qual erigiu sua teoria de conhecimento, considerando que a aritmética e a ciência da natureza (physica) são proposições sintéticas a priori em seus princípios. Kant, por exemplo, não conheceu a obra de Charles Darwin (18091882), pois, se fosse facultado a Kant essa possibilidade, provavelmente teria caminhado para outra direção quanto ao conceito de juízos a priori, conforme demonstrou Lorenz (1988).

Kant tentou romper com a rigidez dos opostos racionalismo versus empirismo, mas antes Descartes abriu as portas para a modernidade. No entanto, o dualismo cartesiano não pode ser posto como absoluto, apesar de sua contribuição para os avanços da ciência ainda hoje. Descartes tinha como foco apenas a questão do conhecimento; já Kant conseguiu transbordar os conceitos do conhecimento para a prática, para a convivência entre os homens.

O que apontamos agora é que cada homem está situado num tempo e numa época; é produto desse tempo e dessa época, mas pode deixar sua marca singular na história, inclusive contribuindo para mudar o mundo das ideias e das ações consequentes. Descartes abre caminho para a modernidade, pós-período medieval; Kant salta da modernidade para abrir as portas do mundo contemporâneo.

Não queremos entrar na questão de comparações de filosofias. Quem vem depois tem sempre o privilégio de ingressar num mundo de maior conhecimento. Kant estava num mundo de informações as quais Descartes não possuía. Seria deselegante estabelecer uma crítica ao cartesianismo com base no kantismo. Descartes, como outros racionalistas, bem como empiristas que antecederam Kant, deixaram matéria-prima para Kant. O conhecimento é universal, é como uma teia que vai sendo tecida por várias mãos. Os nós que estão no centro da teia hoje necessariamente não serão os que estarão no centro num futuro, já que essa teia tende, como tem mostrado a história, a se expandir. No entanto, é bom salientar que os nós mais antigos, que estão na periferia dessa teia são de fato os nós que amarram a teia e a sustentam firme. Assim, toda construção do conhecimento é uma contribuição à teia universal do saber.

Nesse sentido, o sonho que Descartes teve em 10 de novembro de 1619, junto com o que havia pensado naquele dia sobre a construção de uma ciência admirável foi transformado em realidade. E o despertar do sono dogmático fez Kant saltar de uma fase que seus comentadores chamam de pré-crítica para crítica. 
Assim, tanto o sonho de um como o despertar do outro trouxe novos ares para a filosofia e teoria do conhecimento, já que tanto o sonho quanto o despertar foram minar dogmas ou certezas existentes.

Sem dúvida, há algo místico na interpretação do sonho de Descartes e nas possibilidades que ele acalentou a partir da data memorável, como que embuido de uma missão pelo "Alto". Já Kant queria despir o conhecimento de toda aura religiosa ou teológica. Tempos diferentes. Isso é muito. Já se passaram mais de 300 anos de Descartes e mais de 200 anos de Kant. Essas obras ainda estão vivas, ou melhor, nós a mantemos vivas porque elas têm o que oferecer ainda para o aprendizado da vida e o aprendizado filosófico.

Uma última conjectura. Kant dedicou a Francis Bacon a Crítica da razão pura, a partir da segunda edição, embora no Prefácio da primeira edição tenha começado com palavras semelhantes que Bacon introduziu a Grande Instauração.

Para Spinelli (2010, p. 102-103) o que levou Kant a dedicar sua obra a Bacon é porque, semelhante a Bacon, Kant tinha também o ideal de instaurar ou fundar ou reformar os limites e as possibilidades da inteligência humana quanto ao conhecimento.

Nossa conjectura, a qual não exclui a conclusão de Spinelli, vai a outra direção. Nossa hipótese ou nossa conjectura ousada é que Kant dedicou a Crítica da razão pura a Bacon porque nele encontrou o principal motivo para elaborar a síntese do racionalismo com o empirismo quando se defrontou com o aforismo $\mathrm{XCV}$ :

Os que se dedicaram às ciências foram ou empíricos, ou dogmáticos. Os empíricos, à maneira das formigas, acumulam e usam as provisões; os racionalistas; à maneira das aranhas, de si mesmos extraem o que lhes serve para a teia. A abelha representa a posição intermediária: recolhe a matéria-prima das flores do jardim e do campo e com seus próprios recursos a transforma e digere. Não é diferente o labor da verdadeira filosofia, que se não serve unicamente das forças da mente nem tampouco se limita ao material fornecido pela história natural ou pelas artes mecânicas, conservado intato na memória. Por isso muito se deve esperar da aliança estreita e sólida (ainda não levada a cabo) entre essas duas faculdades, a experimental e a racional (BACON, 1999, p. 76).

Kant provavelmente leu a obra de Bacon e ao ler o aforismo acima teria tido o seguinte insight: Bacon propôs uma nova ciência, com um novo método, o indutivo (Novum Organum). E considerando que havia instaurado uma nova ciência, após a varredura dos Ídolos, Bacon comparou os filósofos com as formigas (empíricos) e as aranhas (racionalistas), guardando para si o atributo de abelha, que recolhe o néctar e o digere transformando-o em mel, ou seja, uma nova visão sobre o conhecimento e domínio da natureza.

Kant, entretanto, percebeu que o método proposto por Bacon não diferenciou em essência da indução iniciada por Aristóteles e praticada até então. Bacon, a rigor, manteve-se com seu método indutivo, embora aperfeiçoado em relação ao proposto por Aristóteles, isto é, continuou a ser "formiga". Essa percepção de Kant também foi confirmada porque mesmo com o esforço de Bacon a origem do conhecimento continuava sendo o objeto. Kant discerniu então que poderia desenvolver uma teoria do conhecimento fazendo a síntese da formiga com a aranha, ou seja, a abelha que colhe o material da natureza e o transforma num produto exclusivo da abelha, o mel. Kant compreendera que o sujeito deveria ser o centro e a origem do conhecimento e sua compreensão ou conhecimento do mundo deveria ser conforme amoldado pelo intelecto. Uma solução copernicana. 


\section{REFERÊNCIAS}

BACON, Francis. Novum organum ou verdadeiras indicações acerca da interpretação da natureza. São Paulo: Nova Cultural, 1999, p. 23-218. (Col. Os Pensadores).

BUFF, Luci. Sonhos sobre meditações de Descartes. São Paulo: Annablume, 2001.

154 DESCARTES, René. Discurso do método para bem conduzir a própria razão e procurar a verdade nas ciências. In: DESCARTES, René. Discurso do método, meditações, objeções e respostas, paixões da alma. São Paulo: Abril Cultural, 1973a, pp. 33-79. (Col. Os Pensadores, XV).

DESCARTES, René. Meditações concernentes à primeira filosofia nas quais a existência de Deus e a distinção do real entre alma e o corpo do homem são demonstradas. In: DESCARTES, René. Discurso do método, meditações, objeções e respostas, paixões da alma. São Paulo: Abril Cultural, 1973b, pp. 81-150. (Col. Os Pensadores, XV).

FREUD, Sigmund. Carta a Maxim Leroy sobre um sueño de Descartes (1929). In: FREUD, S. Obras completas. Madrid: Biblioteca Nueva, 1973, Tomo III, p. 3095-3095.

KANT, Immanuel. Crítica da razão pura. São Paulo: Nova Cultural, 1999. (Col. Os Pensadores).

KANT, Immanuel. Prolegômenos a qualquer metafísica futura que possa apresentar-se como ciência. São Paulo: Estação Liberdade, 2014.

LORENZ, Konrad. Vivir es aprender: Franz Kreuzer dialoga com Konrad Lorenz. Barcelona: Gedisa, 1988.

PADOVANI, Umberto; CASTAGNOLA, Luis. História da filosofia. 10. ed. São Paulo: Melhoramentos, 1974.

POPPER, Karl. O que é dialética? In: POPPER, Karl. O racionalismo crítico na política. Brasília: Editora Universidade de Brasília, 1981, p. 25-60.

RAEPER, William; SMITH, Linda. Introdução ao estudo das ideias. 2. ed. São Paulo: Loyola, 2001.

SPINELLI, Miguel. O projeto da grande instauração de Francis Bacon e por que Kant lhe dedicou a Crítica. Veritas, Porto Alegre, v. 55, n. 2, maio/ago, p. 88-107, 2010.

ZAGO, José. O porquê de a crítica da razão pura conduzir, necessariamente, à ciência, com base nas seções de IV a VI da introdução da Crítica da razão pura de Kant. Paradigmas: Filosofia, Realidade \& Arte, Santos, Ano XV, nº 41, p. 21-24, 2014. 